\title{
Pendekatan Box - Whisker Plot dan Regresi Liniear untuk Prediksi User Upgrade pada Start Up AyoCPNS
}

\author{
Puspa Miladin Nuraida Safitri A. Basid, Fajar Rohman Hariri
}

\begin{abstract}
Many start-ups in Indonesia began to become an important part of an economy. In the implementation of startups is still developing and requires a lot of funding for operational. So these start-up companies need to think about steps to survive and develop. Besides through investors, they also carry out promotional steps to attract users. To do the promotion itself, this startup needs to learn how the impact of the promotion that has been done. It's enough or not, it can be seen from the number of users per day. Besides predicting users who will upgrade the premium account also need to be done. This research has produced an equation to make these predictions using linear regression and Box-Whisker Plots.
\end{abstract}

Index Terms - Box-Whisker Plots, linear regression, start-up

Abstrak-- Munculnya banyak start up di indonesia mulai menjadi bagian penting dari perekonomian sebuah negara. Dalam pelaksanaanya perusahaan rintisan seperti ini masih berkembang dan membutuhkan banyak pendanaan untuk operasionalnya. Sehingga para perusahaan rintisan ini perlu memikirkan langkah untuk berkembang lagi. Selain melalui investor, merka juga melakukan langkah promosi untuk menarik user. Untuk melakukan promosi itu sendiri, perusahaan rintisan ini perlu memperhatikan bagaimana dampak dari promosi yang telah dilakukan. Sudah cukup atau belum, hal tersebut dapat di lihat dari jumlah user perharinya. Selain itu memprediksi user yang akan upgrade accont premium juga perlu dilakukan. Penelitian ini telah menghasilkan persamaan untuk melakukan prediksi tersebut dengan menggunakan metode regresi linier dan Box-Whisker Plot.

Kata Kunci-Box-Whisker Plot, regresi linier, , start up

\section{INTRODUCTION}

D ewasa ini, banyak bermunculan start-up baru di kalangan penduduk indonesia. Apabila membahas tentang start-up, mak yang akan muncul di benak

Manuscript received March 05, 2020.This work was supported in part by Informatics Engineering Department of Maulana Malik Ibrahim Islamic State University.

Puspa Miladin Nuraida Safitri.A.B Author is with the Informatic Engineering Departement of Maulana Malik Ibrahim Islamic State University , Malang, Indonesia; email puspa.miladin@uinmalang.ac.id

Fajar Rohman Hariri Author, was Informatic Engineering Departement of Maulana Malik Ibrahim Islamic State University. (email: dosendeso@gmail.com). kita adalah beberapa perusahaan yang sudah dikenal seperti Gojek, Tokopedia, Tiket.com, Traveloka dan lain sebagainya. Start-up sendiri adalah perusahaan rintisan yang meluncurkan produk inovatif [1]. Di indonesia sendiri mulai banyak bermunculan start-upa berbasis teknologi digital. Mereka muncul dengan berbagai inovasi yng dibutuhkan oleh masyarakat. Mulai dari start-up aplikasi pelayanan cuci mobil hingga start-up yang menawarkan bimbingan belajar secara online. Salah satunya adalah website ayocpns yang menawarkan produk layanan bimbingan belajar secara online bagi masyarakat yang akan mengikuti ujian cpns.

Perusahaan rintisan seperti ini secara tidak disadari mulai menjadi bagian penting dari perekonomian sebuah negara [2]. Namun, dalam pelaksanaanya perusahaan rintisan seperti ini masih berkembang dan membutuhkan banyak pendanaan untuk operasionalnya. Beberapa perusahaan rintisan memanfaatkan investor untuk melakukan pendanaan. Namun bila ditelisik lebih dalam, untuk menjaring investor hal yang perlu diperhatikan adaah seberapa banyak user yang tertarik menggunakan layanan dari perusahaan ini. Ini juga merupakan salah satu problema yang dihadapi oleh perusahaan rintisan selain pendanaan [3]. Peneliti menganggap pemasaran produk atau layanan masih memegang kunci utama dalam menggaet pengguna. Dalam melakukan pemasaran produk atau layanan sebuah start-up, penulis menganggap perlunya sebuah prediksi jumlah pengguna. Hal ini salah satunya ditujukan untuk menjadi tolak ukur seberapa efektifkah pemasaran yang dilakukan sehingga pemasaran lebih optimal dan tidak mengalami pemborosan.

Salah satu perusahan rintisan yang sedang naik daun saat ini adalah website ayocpns.com. Jika diliat dari awal rilis (November, 2019) hingga kini (Februari 2020) memiliki pengguna sejumlah 287.000 , hanya $60-75 \%$ user yang mau meng-upgrade accountnya menjadi account premium berbayar. Sehingga perlu menentukan seberapa banyak pemasaran yang harus dilakukan. Peneliti menganggap perlu adanya cara untuk menentukan prediksi jumlah user untuk upgrade ke account premium sebagai acuan pelaksaanan pemasaran.

Pada penelitian ini, penulis melakukan prediksi jumlah user upgrade pada perusahaan rintisan ayocpns 
menggunakan regresi liniear. Namun sebelum itu perlu diterapkan pendekatan Box - Whisker Plot untuk data cleaning agar memperoleh hasik prediksi yang maksimal. Hal ini diharapkan dapat membantu perusahaan rintisan ini untuk merencanakan teknik pemasaran ang lebih optimal.

\section{LITERATURE REVIEW}

Prediksi adalah estimasi atau perkiraan mengenai suatu keadaan yang akan datang. Salah satu keuntungan melakukan prediksi adalah untuk merencanakan langkah selanjutnya atau kebutuhan yang akan dibutuhkan mendatang. Dalam melakukan prediksi berkaitan langsung dengan "apa yang diminta" dan "berapa banyak dan kapan harus disediakan" [4]. Salah satu teknik untuk melakukan prediksi adalah menggunakan regresi liniear. Metode ini merupakan bentuk hubungan variabel bebas $\mathrm{X}$ atau variabel $\mathrm{Y}$ sebagai faktor berpangkat satu. Pada regresi linier sederhana, satu variabel independen dan satu variabel dependen terlibat [5]. Variabel yang akan diprediksi disebut sebagai variabel respon, sedangkan variabel yang menerangkan disebut variabel bebas [6]. Variabel respon $\mathrm{Y}$ dan variabel bebas $\mathrm{X} 1, \mathrm{X} 2, \mathrm{X} 3, \ldots, \mathrm{Xn}$ memiliki hubungan dapat dilihat pada persamaan model regresi liniear adalah sebagai berikut:

$y_{i}=\beta_{0}+\beta_{1} X_{I}+\varepsilon_{i}, \mathrm{i}=1,2, \ldots \ldots, \mathrm{n}$

Namun sebelum melakukan prediksi dengan regresi linear, peneliti menganggap perlunya melakukan analisis data dengan menggunakan metode Box Whisker Plot. Tujuanya dalah untuk menegtahui pemusatan dan sebaran data dari nilai tengah dan nilai outliernya. Peneliti menganggap dengan adanya outlier pada data yang akan diolah, menjadi penyebab model regresi kurang baik. Maka penulis berendapat perlu dilakukan pendeteksian outlier pada data.

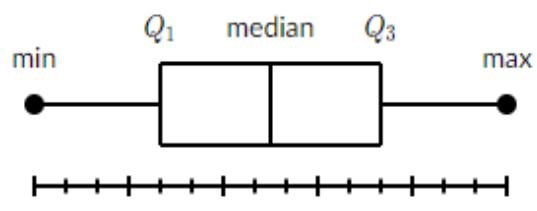

Gambar. 1. Model Box - Whisker Plot [8]

Garis vertical bagian kiri box menunjukan kuartil pertama (Q1), sementara kanan menunjukan kuartil ketiga (Q3). Sedangkan box ialah bidang yang merepresentasikan interquartile range (IQR), atau bagian tengah. Lebar bagian box ini ditentukan oleh IQR. IQR merupakan representasi dari ukuran sebaran data. Apabila ukuran box semakin lebar, menunjukkan data sebaran data semakin lebar. Sedangkan garis horizontal yang melewati bidang box merepresentasikan median dari data. Kemudian garis yang mempertinggi bagian box disebut whiskers. Whiskers inilah yang menunjukan nilai lebih rendah dan lebih tinggi dari data IQR. Untuk panjang garis Whisker bagian atas ini adalah $\leq \mathrm{Q} 3+$ (1.5 x IQR). Panjang garis Whisker bagian kiri adalah $\geq \mathrm{Q} 1-(1,5 \times \mathrm{IQR})$. Pada akhirnya nilai yang berada di kanan atau kiri whisker disebut dengan nilai outlier.

\section{METHOD}

Dalam pelaksanaannya, diagram blok pada gambar 2 menunjukan bagaimana alur kerja dari penelitian ini. Dimulai dari inputan data yang merupaka data user pengguna website ayocpns. Kemudian menentukan nilai a yang merupakan data user non upgrade dan b adalah data user upgrade account premium. Data yang di ambil adalah data perhari mulai november 2019 hingga februari 2020.

Kemudian langkah selanjutnya adalah melakukan data cleaning untuk menentukan nilai ekstrem/outlier dengan metode box-whisker plot. Setelah data didapat maka ditentukan nilai a dan b untuk mendapatkan persamaan regresi linear. Setelah itu barulah prediksi dapat ditentukan dengan menggunaan persamn regresi linear yang sudah ada.

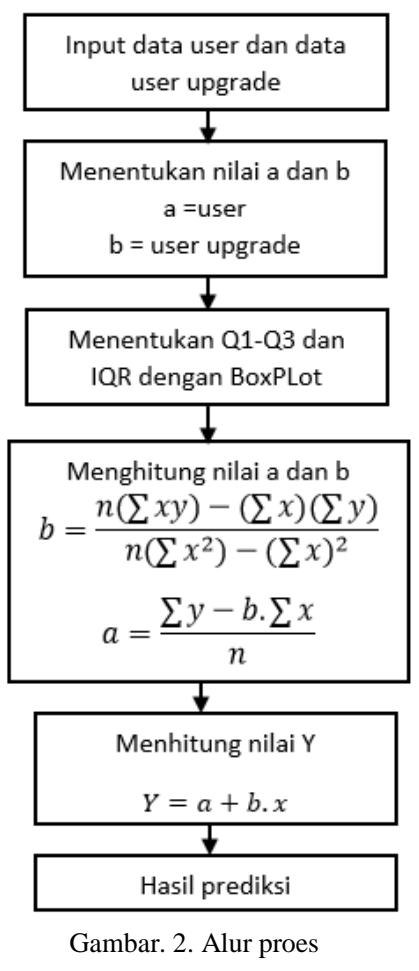

\section{EXPERIMENTAL RESULT}

\section{A. Box-Whisker Plot}

Data mentah user yang diperoleh dari website ayocpns berjumlah 120 , beberapa terdapat data yang ekstrem. Dikatakan data ekstrem adalah ketika pada periode hari tersebut tidak ada data yang masuk, tidak ada user yang upgrade account premium, dan jumlah data yang terlalu besar disbanding data lainya. Hal ini d anggap akan mengakibatkan hasil prediksi yang kurang baik, sehingga dilakukan proses data cleaning untuk mengilangkan data ekstrem tersebut. Tujuanya adalah guna merubah data ke menjadi suatu format yang nantinya akan membuat proses lebih efektif untuk mendapatkan nilai prediksi yang lebih akurat. Selain itu hal ini juga akan mengurangi waktu perhitungan untuk 
data berskala besar. Tabel 1 menunjukan sampel data awal sebelum dilakukan proses Box-Whisper Plot.

Table 1. Sampel data user

\begin{tabular}{|c|c|c|}
\hline Waktu & User Register & User Upgrade Premium \\
\hline $01 / 11 / 2019$ & 38 & 37 \\
\hline $04 / 11 / 2019$ & 2 & 1 \\
\hline 07/11/2019 & 1 & 1 \\
\hline $10 / 11 / 2019$ & 1 & 1 \\
\hline $11 / 11 / 2019$ & 11 & 7 \\
\hline $12 / 11 / 2019$ & 1 & 1 \\
\hline $18 / 11 / 2019$ & 39 & 1 \\
\hline $19 / 11 / 2019$ & 17 & 3 \\
\hline $20 / 11 / 2019$ & 6 & 2 \\
\hline $21 / 11 / 2019$ & 6 & 1 \\
\hline $22 / 11 / 2019$ & 5 & 3 \\
\hline $23 / 11 / 2019$ & 905 & 119 \\
\hline 24/11/2019 & 924 & 221 \\
\hline $25 / 11 / 2019$ & 663 & 178 \\
\hline $26 / 11 / 2019$ & 1028 & 151 \\
\hline $27 / 11 / 2019$ & 482 & 117 \\
\hline 28/11/2019 & 309 & 78 \\
\hline $29 / 11 / 2019$ & 242 & 71 \\
\hline $30 / 11 / 2019$ & 304 & 61 \\
\hline $01 / 12 / 2019$ & 180 & 53 \\
\hline $02 / 12 / 2019$ & 655 & 93 \\
\hline $04 / 12 / 2019$ & 577 & 99 \\
\hline 05/12/2019 & 407 & 89 \\
\hline 06/12/2019 & 443 & 76 \\
\hline 07/12/2019 & 627 & 77 \\
\hline 08/12/2019 & 1257 & 165 \\
\hline 09/12/2019 & 944 & 164 \\
\hline $10 / 12 / 2019$ & 710 & 160 \\
\hline $26 / 01 / 2020$ & 2998 & 406 \\
\hline $27 / 01 / 2020$ & 6928 & 952 \\
\hline $28 / 01 / 2020$ & 6451 & 1149 \\
\hline $29 / 01 / 2020$ & 6660 & 830 \\
\hline $30 / 01 / 2020$ & 10351 & 1962 \\
\hline $31 / 01 / 2020$ & 9861 & 2708 \\
\hline $01 / 02 / 2020$ & 7008 & 1737 \\
\hline $02 / 02 / 2020$ & 7664 & 1715 \\
\hline $03 / 02 / 2020$ & 9442 & 2050 \\
\hline $04 / 02 / 2020$ & 9250 & 2506 \\
\hline $05 / 02 / 2020$ & 12537 & 2259 \\
\hline $06 / 02 / 2020$ & 12975 & 1986 \\
\hline $07 / 02 / 2020$ & 10265 & 1808 \\
\hline
\end{tabular}
Plot seperti di bawah ini:

$Q 3+(1,5 . I Q R)<$ outlier $\leq Q 3+(3 . I Q R)$
$Q 1-(1,5 . I Q R)<$ outlier $\leq Q 1-(3 . I Q R)$

Diperoleh nilai:

$\mathrm{Q} 1=740,75$

$\mathrm{Q} 3=3185,75$

$\mathrm{IQR}=2445$

Batas bawah $=$ Q1-(1,5 x IQR $)=-2926,75$

Batas atas $=\mathrm{Q} 3+(1,5 \times \mathrm{IQR})=6853,25$

\begin{tabular}{cc}
924 & 221 \\
663 & 178 \\
1028 & 151 \\
482 & 117 \\
309 & 78 \\
242 & 71 \\
304 & 61 \\
180 & 53 \\
655 & 93 \\
704 & 117 \\
577 & 99 \\
407 & 89 \\
443 & 76 \\
627 & 77 \\
1257 & 165 \\
944 & 164 \\
710 & 160 \\
736 & 199 \\
\hline \hline
\end{tabular}

\section{B. Regresi Liniear}

Metode ini memiliki tujuan untuk menguji sejauh mana hubungan antara variable penyebab (x) dan variable respon (y). Persamaan dari metode ini digambarkan seperti berikut:

$Y=a+b \mathrm{X}$

$b=\frac{n\left(\sum x y\right)-\left(\sum x\right)\left(\sum y\right)}{n\left(\sum x^{2}\right)-\left(\sum x\right)^{2}}$

$a=\frac{\sum y-b \cdot \sum x}{n}$

$\mathrm{y}=$ variable respon

$\mathrm{x}=$ variabel bebas

$\mathrm{a}=$ konstanta

$\mathrm{b}=$ besaran respon yang disebabkan oleh variable bebas.

$\mathrm{n}=$ jumlah data

$\sum \mathrm{y}=$ jumlah data $\mathrm{y}$

$\sum x y=$ jumlah data $x y$

Setelah data diolah dengan persamaan di atas, maka nilai:

$a=-39,9811382$

$\mathrm{b}=0,206609087$

sehingga persamaan untuk menentukan prediksi user upgrade account premium pada website ayopns adalah

$y=-39,9811382+0,206609087 . X$

$\mathrm{X}$ pada persamaan di atas merupak jumlah awal user yang tidak melakukan upgrade account.

Table 3. Data Prediksi dan MAE

\begin{tabular}{llllll}
\hline $\begin{array}{c}\text { User } \\
\text { Register }\end{array}$ & $\begin{array}{c}\text { User } \\
\text { Upgrade } \\
\text { Premium }\end{array}$ & $\begin{array}{c}\text { REGRESI } \\
\text { (Prediksi) }\end{array}$ & REAL & MAE & MSE \\
\hline 704 & 117 & 105,4717 & 117 & 11,52834 & 132,9026 \\
577 & 99 & 79,23231 & 99 & 19,76769 & 390,7618 \\
407 & 89 & 44,10876 & 89 & 44,89124 & 2015,223 \\
443 & 76 & 51,54669 & 76 & 24,45331 & 597,9645 \\
627 & 77 & 89,56276 & 77 & 12,56276 & 157,8229 \\
1257 & 165 & 219,7265 & 165 & 54,72648 & 2994,988 \\
944 & 164 & 155,0578 & 164 & 8,94216 & 79,96222 \\
710 & 160 & 106,7113 & 160 & 53,28869 & 2839,684 \\
736 & 199 & 112,0832 & 199 & 86,91685 & 7554,539 \\
790 & 152 & 123,24 & 152 & 28,75996 & 827,1353 \\
943 & 132 & 154,8512 & 132 & 22,85123 & 522,1788 \\
714 & 126 & 107,5378 & 126 & 18,46225 & 340,8547 \\
892 & 81 & 144,3142 & 81 & 63,31417 & 4008,684 \\
\hline
\end{tabular}




\begin{tabular}{|c|c|c|c|c|c|}
\hline 1241 & 229 & 216,4207 & 229 & 12,57926 & 158,2378 \\
\hline 1356 & 282 & 240,1808 & 282 & 41,81922 & 1748,847 \\
\hline 1226 & 290 & 213,3216 & 290 & 76,6784 & 5879,577 \\
\hline 1055 & 251 & 177,9914 & 251 & 73,00855 & 5330,249 \\
\hline 891 & 191 & 144,1076 & 191 & 46,89244 & 2198,901 \\
\hline 755 & 169 & 116,0087 & 169 & 52,99128 & 2808,075 \\
\hline 1411 & 157 & 251,5443 & 157 & 94,54428 & 8938,622 \\
\hline 2473 & 578 & 470,9631 & 578 & 107,0369 & 11456,89 \\
\hline 1614 & 509 & 293,4859 & 509 & 215,5141 & 46446,31 \\
\hline 1395 & 80 & 248,2385 & 80 & 168,2385 & 28304,21 \\
\hline 1531 & 683 & 276,3374 & 683 & 406,6626 & 165374,5 \\
\hline 1564 & 470 & 283,1555 & 470 & 186,8445 & 34910,88 \\
\hline 1598 & 452 & 290,1802 & 452 & 161,8198 & 26185,65 \\
\hline 1716 & 449 & 314,5601 & 449 & 134,4399 & 18074,1 \\
\hline 1658 & 830 & 302,5767 & 830 & 527,4233 & 278175,3 \\
\hline 1963 & 1076 & 365,5925 & 1076 & 710,4075 & 504678,8 \\
\hline 1184 & 300 & 204,644 & 300 & 95,35598 & 9092,763 \\
\hline 1566 & 376 & 283,5687 & 376 & 92,43131 & 8543,547 \\
\hline 1505 & 391 & 270,9655 & 391 & 120,0345 & 14408,27 \\
\hline 1180 & 475 & 203,8176 & 475 & 271,1824 & 73539,9 \\
\hline 1278 & 333 & 224,0653 & 333 & 108,9347 & 11866,77 \\
\hline 1415 & 491 & 252,3707 & 491 & 238,6293 & 56943,93 \\
\hline 1590 & 565 & 288,5273 & 565 & 276,4727 & 76437,15 \\
\hline 2400 & 500 & 455,8807 & 500 & 44,11933 & 1946,515 \\
\hline 1732 & 431 & 317,8658 & 431 & 113,1342 & 12799,35 \\
\hline 1618 & 442 & 294,3124 & 442 & 147,6876 & 21811,64 \\
\hline 1554 & 445 & 281,0894 & 445 & 163,9106 & 26866,69 \\
\hline 1427 & 314 & 254,85 & 314 & 59,14997 & 3498,719 \\
\hline 2050 & 301 & 383,5675 & 301 & 82,56749 & 6817,391 \\
\hline 2594 & 740 & 495,9628 & 740 & 244,0372 & 59554,14 \\
\hline 2027 & 490 & 378,8155 & 490 & 111,1845 & 12362 \\
\hline 2198 & 535 & 414,1456 & 535 & 120,8544 & 14605,78 \\
\hline 2032 & 484 & 379,8485 & 484 & 104,1515 & 10847,53 \\
\hline 1604 & 365 & 291,4198 & 365 & 73,58016 & 5414,04 \\
\hline 1519 & 338 & 273,8581 & 338 & 64,14193 & 4114,188 \\
\hline 1979 & 425 & 368,8982 & 425 & 56,10175 & 3147,407 \\
\hline 3222 & 538 & 625,7133 & 538 & 87,71334 & 7693,63 \\
\hline 3608 & 606 & 705,4644 & 606 & 99,46445 & 9893,177 \\
\hline 3202 & 617 & 621,5812 & 617 & 4,581159 & 20,98702 \\
\hline 3137 & 590 & 608,1516 & 590 & 18,15157 & 329,4794 \\
\hline 2607 & 590 & 498,6488 & 590 & 91,35125 & 8345,05 \\
\hline 2998 & 406 & 579,4329 & 406 & 173,4329 & 30078,97 \\
\hline 4206 & 723 & 829,0167 & 723 & 106,0167 & 11239,54 \\
\hline 4139 & 654 & 815,1739 & 654 & 161,1739 & 25977,02 \\
\hline 3988 & 559 & 783,9759 & 559 & 224,9759 & 50614,16 \\
\hline 4363 & 586 & 861,4543 & 586 & 275,4543 & 75875,08 \\
\hline 3528 & 508 & 688,9357 & 508 & 180,9357 & 32737,74 \\
\hline 3033 & 462 & 586,6642 & 462 & 124,6642 & 15541,17 \\
\hline 2674 & 489 & 512,4916 & 489 & 23,49156 & 551,8534 \\
\hline \multirow[t]{4}{*}{2170} & 377 & 408,3606 & 377 & 31,36058 & 983,4861 \\
\hline & & & & 102,365 & 22808,52 \\
\hline & & & MAE & & \\
\hline & & & MSE & & \\
\hline
\end{tabular}

\section{CONCLUSION}

Berdasarkan penelitian yang telah dilakukan, di dapatkan persamaan untuk prediksi user upgrade premium account yaitu $\mathrm{y}=-39,9811382+0,206609087$ .X. Hasil prediksi dari persamaan ini dapat digunakan sebagai acuan untuk melakukan kegiatan promosi guna meningkatkan user yang melakukan upgrade account pada website ayocpns. Dari persamaan tersebut juga setelah dilakukan ujicoba di dapatkan nilai MAE sebesar 102,365 dan MSE 22808,52 sehinngga dianggap cukup akurat.

\section{REFERENCES}

[1] E. Klotins, M. Unterkalmsteiner, and T. Gorschek, "SoftwareIntensive Product Engineering in Start-Ups: A Taxonomy," IEEE Softw., vol. 35, no. 4, pp. 44-52, 2018, doi: 10.1109/MS.2018.2801548.

[2] S. Srinivasan, I. Barchas, M. Gorenberg, and E. Simoudis, "Venture Capital: Fueling the Innovation Economy," Computer (Long. Beach. Calif),, vol. 47, no. 8, pp. 40-47, 2014, doi: 10.1109/MC.2014.230.

[3] C. Giardino, S. S. Bajwa, X. Wang, and P. Abrahamsson, "Key Challenges in Early-Stage Software Startups," Springer Int. Publ., vol. 212, pp. 52-63, 2015, doi: 10.1007/978-3-31918612-2.

[4] V. Gaspersz, Production Planning And Inventory Control. Jakarta: PT. Gramedia Pustaka Utama, 2005.

[5] M. S. Acharya, A. Armaan, and A. S. Antony, "A comparison of regression models for prediction of graduate admissions," ICCIDS 2019 - 2nd Int. Conf. Comput. Intell. Data Sci. Proc., pp. 1-5, 2019, doi: 10.1109/ICCIDS.2019.8862140.

[6] D. N. Gujarati, Dasar-Dasar Ekonometrika, 1st ed. Jakarta: Penerbit Erlangga, 2007.

[7] N. Draper and H. Smith, Applied Regresssion Analysis, 2nd ed. Jakarta: Gramedia Pustaka Utama, 1992.

[8] K. Academy, "Box-Plot Review." [Online]. Available: https://www.khanacademy.org/math/statisticsprobability/summarizing-quantitative-data/box-whiskerplots/a/box-plot-review.

Dari hasil prediksi yang diperoleh, kemudan di tentukan nilai MAE dan MSE nya. MAE dan MSE merepresentasikan rata - rata kegagalan (eror) absolut dari hasil peramalan dengan nilai sebenarnya. 